\title{
IN VITRO ANTHELMINTIC AND ANTI-AMYLASE PROPERTIES OF GARCINIA PEDUNCULATA ROXB. ETHANOLIC EXTRACT
}

\author{
PINKY SARMAH ${ }^{1}$, NAKO KOBING ${ }^{1}$, JYOTCHNA GOGOI ${ }^{*}$, ANANTA MADHAB DUTTA ${ }^{2}$ \\ ${ }^{1}$ Department of Biochemistry and 2Department of Chemistry, Assam Down Town University, Guwahati 781026, India \\ Email: jyotchnagogoi@gmail.com
}

Received: 26 Sep 2016 Revised and Accepted: 17 Nov 2016

\section{ABSTRACT}

Objective: The present study aims to investigate in vitro anthelmintic and anti-amylase properties of the ethanolic fruit extract of Garcinia pedunculata.

Methods: For the study, mature fruits of G. pedunculata were collected from local markets during April-May. Fleshy pericarps of fruits were chopped into small pieces, dried and extracted by using a Soxhlet apparatus. Ethanol extract of $G$. pedunculata was used for evaluation of in vitro anthelmintic and anti-amylase activities. In vitro anthelmintic activity was evaluated in animal models, Pheretima posthuma, an earthworm species. In vitro anti-amylase activity was evaluated by using zymographic, achromic point analysis (Starch-Iodine method) and spectrophotometric method [Di Nitro Salicylic acid (DNS)-Maltose method].

Results: Ethanolic extract of $G$. pedunculata showed anthelmintic activity at a concentration of $75 \mathrm{mg} / \mathrm{ml}$, paralysis and death timing was reported at $0.62 \pm 0.26 \mathrm{~min}$ and $1.42 \pm 0.07 \mathrm{~min}$, respectively. The reference standard (Albendazole) showed paralysis time: $2.13 \pm 0.28 \mathrm{~min}$ and death time: $5.12 \pm 0.29 \mathrm{~min}$. In the anti-amylase study, a zymographic density analysis of $G$. pedunculata showed significant variation in band intensity as compared to Starch-Iodine achromic point analysis and DNS-Maltose method. A concentration of $1.5 \mathrm{mg} / \mathrm{ml}$ of extract showed inhibition of amylase: $67.65 \pm 1.53 \%$ as compared to other concentrations and control sets.

Conclusion: It could be concluded that ethanolic extract of G. pedunculata has biological properties which could be utilised in medicine by characterising its bioactive components.

Keywords: Anti-amylase activity, Anthelmintic activity, Garcinia pedunculata

(C) 2017 The Authors. Published by Innovare Academic Sciences Pvt Ltd. This is an open access article under the CC BY license (http://creativecommons.org/licenses/by/4. 0/) DOI: http://dx.doi.org/10.22159/ijpps.2017v9i1.15395

\section{INTRODUCTION}

In North East India, 9 species of the genus Garcinia (Thekera tenga) have been reported in 1934 which are mainly used in food by different communities $[1,2]$. Out of the 9 species, 8 species alone have been reported from the Sonitpur district of Assam [2]. The genus belongs to the family Clusiaceae, the members of this genus are mainly evergreen trees or shrubs with greenish gum resins. They are used in many health problems by different communities like, Kau (G. cowa Roxb.) and Kuji (G. morella Desr.) thekera tenga are used in the treatment of dysentery by Assamese and Bodo people [3]. Bor thekera tenga (G. pedunculata Roxb.) has been used for Diabetes mellitus (DM) by Rabha, Karbi and Missing communities [4]. Local traditional healers suggest that, if a patient takes one teaspoon of juice of the G. pedunculata every morning for one week, then the patient would have a normal blood sugar level. But, regular use of this dried peel for a longer time is not suggested because it might cause stomach and constipation problems.

Scientifically, G. pedunculata has been reported to have a good amount of Hydroxycitric acid (HCA) among all Garcinia sp. One of the isomeric forms of HCA has been reported from this plant, might play a role in reducing obesity [5]. With the traditional knowledge of its use in DM, a hypothesis was designed to evaluate its in vitro antiamylase and anthelmintic properties.

Starch, Sodium hydroxide $(\mathrm{NaOH})$, DNS, Sodium sulphite $\left(\mathrm{Na}_{2} \mathrm{SO}_{3}\right)$, Sodium acetate, methanol, ethanol and glacial acetic acid, acrylamide, bis-acrylamide, N,N,N,N-tetramethylene ethylenediamine (TEMED), ammonium persulphate, $0.1 \mathrm{~N}$ iodine solution were purchased from Merck, Mumbai, India. All the chemicals were of analytical grade.

Mature fruits of $G$. pedunculata were collected from local markets during April-May. This fruit is available in the market only in this period of a year, and it was identified by the traditional farmer expert. It is a tall, erect tree which flowers in mid of January. Herbarium of it was prepared in this period by standard procedure [6]. It was deposited for identification in the Botanical Survey of India (BSI), Shillong, Meghalaya and the herbarium was also deposited in the Herbaria Repository of Defence Research Laboratory, Tezpur, Assam. The mature fruits were washed to remove dirt. Fleshy pericarps of the fruits were chopped into small pieces, shade dried and stored in an airtight container. The extraction was carried out by the percolation method using a Soxhlet apparatus, Optics Technology, Delhi, India. The solvent was used to be ethanol. About $100 \mathrm{~g}$ of dried pieces were extracted with $500 \mathrm{ml}$ of ethanol. The extract was concentrated to dryness under a controlled temperature of $40-45^{\circ} \mathrm{C}$. The percentage yield was found to be 15.43 $\%$. The extract was preserved in the refrigerator till further use.

A starch solution $(1 \% \mathrm{w} / \mathrm{v})$ was prepared in $100 \mathrm{ml}$ of $16 \mathrm{mmol}$ of sodium acetate buffer. The enzyme solution was prepared by mixing $1 \mathrm{ml}$ saliva in $19 \mathrm{ml}$ of distilled water. The saliva mix was then filtered by using Whatman filter paper No. 1. The colorimetric reagent DNS was prepared by dissolving $1 \mathrm{~g}$ of DNS in $1 \% \mathrm{NaOH}$ solution containing $200 \mathrm{mg}$ crystalline phenol and $50 \mathrm{mg}$ of $\mathrm{Na}_{2} \mathrm{SO}_{3}$. The test tubes were labelled as a zero min control (Blank), plant extract treated and positive control (untreated amylase). $1 \mathrm{ml}$ of distilled water was added to blank and positive control tubes. Other test tubes contain $1 \mathrm{ml}$ of the extracts with a concentration of $0.5,1$, 1.5 and $2 \mathrm{mg} / \mathrm{ml} .1 \mathrm{ml}$ starch solution was added to all the tubes, followed by $1 \mathrm{ml}$ of saliva and incubated for $15 \mathrm{~min}$ at $25^{\circ} \mathrm{C}$. In the case of the blank, the reaction was stopped by adding $2 \mathrm{ml}$ of DNS solution in zero min. But, in other sets, the reaction was stopped after $15 \mathrm{~min}$ by adding $2 \mathrm{ml}$ DNS solution to each tube. The reaction mixture shows a reduction of DNS to 3-amino-5-nitrosalicylic acid when incubated in boiling water for $5 \mathrm{~min}$. The absorbance of the colour change was detected at $540 \mathrm{~nm}$ by using UV-Visible Spectrophotometer (Systronics, India) [7]. 
The amylase activity can also be detected by running PAGE with 7.5 $\%$ gel under basic native conditions. Five lanes were used, named as positive control (saliva only) lane, $0.5,1.0,1.5$ and $2.0 \mathrm{mg} / \mathrm{ml}$ plant extracts containing lanes with saliva in each. Sample mix of $50 \mu \mathrm{l}$ saliva and $50 \mu \mathrm{l}$ of plant extract was made for loading in the wells, but in the positive control, $50 \mu \mathrm{l}$ of distilled water in place of the extract was added to make equal volume as per the other treatment lanes and labelled as control lane. For zymogram, after electrophoresis, the gel was incubated in gelatinized starch $(2 \%$ prepared in $0.1 \mathrm{M}$ sodium acetate buffer, $\mathrm{pH} 5$ ) for $1 \mathrm{~h}$. Subsequently, the gel was stained with iodine reagent ( $3 \%$ ) for $5 \mathrm{~min}$. The gel was destained by dipping it in destaining solution $(5 \mathrm{ml}$ glacial acetic acid, $45 \mathrm{ml}$ of methanol and $50 \mathrm{ml}$ distilled water) for overnight and observed on the next day for better band detection [8]. Image J software (National Institute of Health, USA) would be used to analyse the percentage inhibition of the enzyme in the zymogram.

The achromic point of salivary amylase helps in determining the activity of the enzyme by taking starch as a substrate which reacts with $1 \%$ iodine solution. $1 \mathrm{ml}$ of an extract of different concentrations $(0.5,1.0,1.5$ and $2.0 \mathrm{mg} / \mathrm{ml})$ was taken on labelled test tubes and $1 \mathrm{ml}$ of saliva with 1:20 dilution was added. The reaction was started by the addition of $1 \mathrm{ml}$ starch and incubated for $15 \mathrm{~min}$ at $25^{\circ} \mathrm{C}$. The control test tube was prepared by stopping the reaction with 2-3 drops of iodine solution to it. Positive control of salivary amylase was prepared by incubating the test tube for $15 \mathrm{~min}$ containing untreated saliva with $1 \mathrm{ml}$ of distilled water. The reaction was stopped by adding 2-3 drops of iodine solution [9]. The colour change was observed, and Image J software (NIH, USA) would be used for analysis of percentage inhibition of the enzyme.

Adult earthworms ( $P$. posthuma) were used to evaluate in vitro anthelmintic activity (worms were identified by veterinary practitioners). Earthworms were collected from cow dung dumping ground near Panikhaiti, Guwahati, Assam. The average size of an earthworm was found to be $6-8 \mathrm{~cm}$. In vitro anthelmintic assay was carried out as per the method [10]. The extract concentrations taken were 25,50 and $75 \mathrm{mg} / \mathrm{ml}$ in distilled water. Each test samples were subjected for triplicate study in $9 \mathrm{~cm}$ Petri dish containing $25 \mathrm{ml}$ of it. Albendazole $(25 \mathrm{mg} / \mathrm{ml})$ was used as the reference standard, and normal saline was used as a control. The effect was marked by the time taken for paralysis when no movement of any sort could be observed, except under vigorous shaking. Time taken for death was also observed and recorded when no movement was observed on vigorous shaking and also when dipped in warm water at $50{ }^{\circ} \mathrm{C}$. All, the results have been expressed as mean \pm SD.

Management of DM is a major challenge for the medical community. Herbal sources of treatment show easier and economical for every sect of society. Thus, researches are carried out for finding the
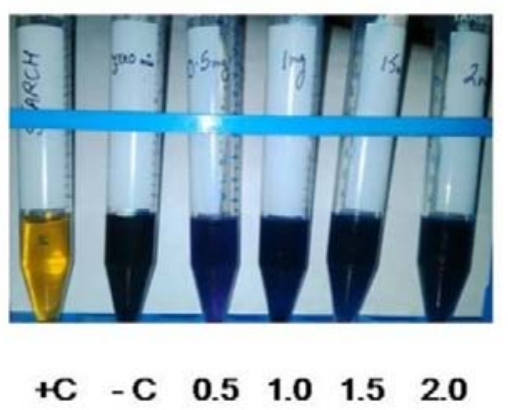

A

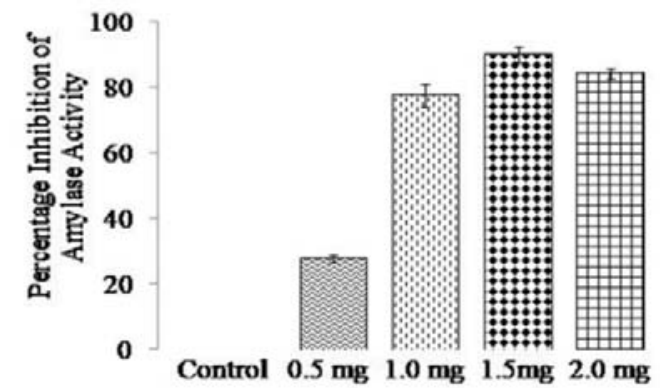

B different herbal source of treatment of DM. Traditionally in Assam, G. morella [2] and G. pedunculata [4] are reported to treat DM. But, no scientific evaluation has been done. Thus, in the present investigation, G. pedunculata was extracted with ethanol to evaluate in vitro anti-amylase activity. The ethanolic extract of $G$. pedunculata showed the presence of flavonoid, polyphenols, carbohydrates and alkaloids in good amount.

$\alpha$-amylase (EC 3.2.1.1) is one of the enzymes which helps in managing the postprandial blood glucose level in type II Diabetes $[11,12]$. Thus, $\alpha$-amylase of saliva was taken for the study, which would directly suggest the in vitro activity of the extract. A comparative analysis of the activities of the enzyme showed variation in the three methods (zymographic, achromic point analysis and DNS-Maltose spectrophotometric method). Zymogram of the enzyme (fig. 1) showed quite a significant variation in band intensity on treating with different concentrations of extract. 1.5 $\mathrm{mg} / \mathrm{ml}$ showed $67.65 \pm 1.53 \%$ of anti-amylase activity as compared

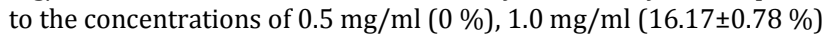
and $2.0 \mathrm{mg} / \mathrm{ml}(14.70 \pm 0.98 \%)$. But, when the starch-iodine method was conducted, no significant variation was observed in antiamylase activities of al the concentrations (fig. 2). The activities were found to be $77.49 \pm 2.31 \%(1.0 \mathrm{mg} / \mathrm{ml}), 90.05 \pm 1.36 \%(1.5$ $\mathrm{mg} / \mathrm{ml})$ and $84.18 \pm 2.11 \%(2.0 \mathrm{mg} / \mathrm{ml})$ in this method. But, in DNSMaltose method, the result was not found to be constant in its replicates. It has been reviewed that, many researchers have used DNS-Maltose method for anti-amylase activity, for example, Ginger [13], Evolvulus alsinoides [14], Psidium guajava [15]. But, this plant did not show similar observation with it.

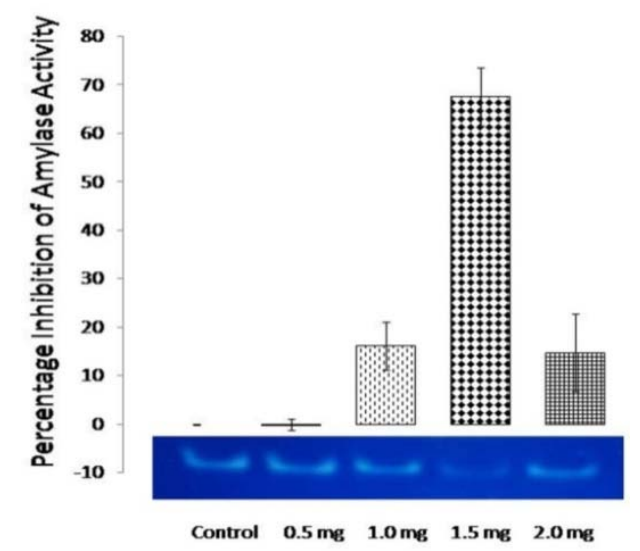

Fig. 1

Fig. 2: Zymogram and densitometric analysis of the anti-amylase activity of different concentration of ethanolic extract of G. pedunculata.
(Lane1: Saliva+distilled water, Lane 2: Saliva+0.5 mg/ml extract, Lane 3; Saliva+1.0 mg/ml extract, Lane 4: Saliva+1.5 mg/ml extract and
Lane 5: Saliva+2.0 mg/ml extract). The experiment was conducted in triplicates. The each histogram is expressed with \pm SD

Fig. 2. Starch-Iodine analysis of amylase activity of the different concentrations of ethanolic extract of $G$. pedunculata. A) Tubes showing the variation in colour intensity, B) Percentage inhibition of the enzyme activity. [Tube $(+C)$ : active saliva, Test tube $(-C)$ : inactive saliva, Tube 0.5 : Active saliva $+0.5 \mathrm{mg} / \mathrm{ml}$ extract, Tube 1.0: Active saliva $+1.0 \mathrm{mg} / \mathrm{ml}$ extract, Tube 1.5: Active saliva $+1.5 \mathrm{mg} / \mathrm{ml}$, Tube $2.0:$ Active saliva $+2.0 \mathrm{mg} / \mathrm{ml}$ extract]. The experiment was conducted in triplicates. The each histogram is expressed with $\pm \mathrm{SD}$. 
For anthelmintic activity, the three animal models that could be used are $P$. posthuma, Ascaridia galli and Raillietina spiralis $[16,17]$. In the study, $P$. posthuma has been used as the animal model because of its anatomical and physiological resemblance to intestinal roundworm $[16,18]$. G. pedunculata showed anthelmintic activity in a dosedependent manner, giving shortest time for paralysis and death at $75 \mathrm{mg} / \mathrm{ml}$ (table 1). The time required for paralysis and death was recorded to be less than the standard (table 1). The anthelmintic activity of ethanolic extract of Evolvulus alsinoides was reported at $50 \mathrm{mg} / \mathrm{ml}$ concentration in $P$. posthuma [17], whereas the methanolic extract of $20 \mathrm{mg} / \mathrm{ml}$ showed the activity in Mentha piperita and Lantana camara [19]. Thus, it can be concluded that the concentrations were optimised for the anthelmintic activity study in G. pedunculata.

Table 1: Effect of ethanol extract of $G$. pedunculata on $P$. posthuma in anthelmintic activity study

\begin{tabular}{llll}
\hline Test substance & Concentration $(\mathbf{m g} / \mathbf{m l})$ & Time taken for paralysis (min) (mean \pm SD) & Time taken for death (min) (mean \pm SD) \\
\hline Ethanolic extract & 25 & $1.16 \pm 0.10$ & $2.80 \pm 1.41$ \\
& 50 & $1.16 \pm 0.02$ & $1.88 \pm 0.41$ \\
& 75 & $0.62 \pm 0.26$ & $1.42 \pm 0.07$ \\
Albendazole & 25 & $2.13 \pm 0.28$ & $5.12 \pm 0.29$ \\
Control & - & Not affected & Not affected \\
(Normal saline) & & & \\
\hline
\end{tabular}

* Values are expressed in mean \pm SD of three samples for each group. Three concentrations $(25,50$ and $75 \mathrm{mg} / \mathrm{ml})$ of ethanolic extract of $G$. pedunculata were used in the study. Reference standard used was Albendazole and normal saline was used as a control group.

G. pedunculata which is an endemic and the critically endangered tree of North East India reported with a good amount of HCA by some researcher. Proper cultivation of it would give a good herbal source for reducing hyperglycemic condition in type II Diabetes. Further scientific elucidation is required to claim its exact dose for reducing DM. In the present study, it can be concluded that zymogram or densitometric study of electrophoretic gel might be a good method for determining the anti-amylase activity of the plant which would help further in the study of the bioactive principles for treatment of type II Diabetes. The extract also shows strong in vitro anthelmintic activity in earthworm which could be further evaluated in other anthelmintic animal models.

\section{ACKNOWLEDGEMENT}

We want to Assam down town University for giving the permission and providing the funds to execute the study. We also, want to thank Ms. Himakshi Borah and Mr. Bulbul Das for their extended support in completion of work.

\section{CONFLICT OF INTERESTS}

\section{Declared none}

\section{REFERENCES}

1. Kanjilal UN, Kanjilal PC, Das A. Flora of Assam V-I. Periodical Expert book Agency, Delhi; 1934. p. 103-10.

2. Baruah S, Borthakur S. Studies on morphology and ethnobotany of six species of Garcinia L. (Clusiaceae) found in the Brahmaputra Valley, Assam, India. J Nat Prod Plant Resour 2012;2:389-96.

3. Patir B, Borah A. Wild edible plants of Assam, Director, Forest Communication, Assam; 2007. p. 10-1.

4. Sarmah PC. Ethno antidiabetic plants of Assam. Int J Appl Biol Pharm Technol 2011;2:246-51.

5. Kagyung R, Gajurel PR, Rethy P, Singh B. Ethnomedicinal plants used for gastrointestinal diseases by Adi tribes of Dehang-Debang biosphere reserve in Arunachal Pradesh. Indian J Traditional Knowledge 2010;9:496-501.

6. Jain SK, Rao RR. A handbook of field and herbarium technique. Today and Tomorrow's Printers and Publishers, New Delhi; 1977.

7. Malik CP, Singh MB. Plant enzymology and histo- enzymology. Kalyani Publisher, New Delhi; 1980. p. 278.

8. Preethi C, Gowda TV. Partial purification and characterization of amylase and starch from Elephant foot Yam [Amorphophallus campanulatus (Roxb.) Blume]. Indian J Biotechnol 2014;13:551-4.
9. Boettcher B, DeLa Lande FA. Electrophoresis of human saliva and identification of inherited variants of amylase isozymes. Aust J Exp Biol Med Sci 1969;47:97-103

10. Ajaiyeoba EO, Onocha PA, Olarenwaju OT. In vitro anthelmintic properties of Buchholzia coriaceae and Gynandropsis gynandra extract. Pharm Biol 2001;39:217-20.

11. Ali H, Houghton PJ, Soumyanath A. $\alpha$-Amylase inhibitory activity of some Malaysian plants used to treat diabetes; with particular reference to Phyllanthus amarus. J Ethnopharmacol 2006;107:449-55.

12. Karthic K, Kirthiram KS, Sadasivam A, Thayumanavan B. Identification of amylase inhibitors from Syzygium cumini Linn seeds. Indian J Exp Biol 2008;46:677-80.

13. Abeysekara WKSM, Chandrasekara A, Liyanage PK. Amylase and Glucosidase enzyme inhibitory activity of Ginger (Zinger Officinale Roscoe) an in vitro study. Trop Agric Res 2007;19:128-35.

14. Gomathi D, Kalaiselvi M, Uma C. In vitro $\alpha$-amylase and $\alpha$ glucosidase inhibitory effects of ethanolic extract of Evolvulus alsinoides (L.). Int Res J Pharm 2013;3:226-9.

15. Manikandan R, Vijaya Anand A, Durai Muthumani G. Phytochemical and in the vitro anti-diabetic activity of methanolic extract of Psidium guajava leaves. Int J Curr Microbiol Appl Sci 2013;2:15-9.

16. Vigar Z. Atlas of medical parasitology. $2^{\text {nd }}$ ed. P. G. Publishing House, Singapore; 1984. p. 242.

17. Dash GK, Suresh P, Kar DM, Ganpaty S, Panda SB. Evaluation of Evolvulus alsinoides Linn. for anthelmintic and antimicrobial activities. J Nat Rem 2002;2:182-5.

18. Shivkumar YM, Kumar VL. Anthelmintic activity of latex of Calotropis procera. Pharm Biol 2003;41:263-5.

19. Girme AS, Bhalke RD, Ghogare PB, Tambe VD, Jadhav RS, Nirmal SA. Comparative in the vitro anthelmintic activity of Mentha piperita and Lantana camara from western India. J Pharm Sci 2006;5:5-7.

\section{How to cite this article}

Pinky Sarmah, Nako Kobing, Jyotchna Gogoi, Ananta Madhab Dutta. In vitro anthelmintic and anti-amylase properties of Garcinia pedunculata Roxb. ethanolic extract. Int J Pharm Pharm Sci 2017;9(1):189-191. 